\title{
Rural Families with a Child Abuse Report are More Likely Headed by a Single Parent and Endure Economic and Family Stress
}

\author{
MARYBETH J. MATTINGLY AND WENDY A. WALSH
}

\section{Key Findings}

The types of child maltreatment in rural families tend to mirror child abuse in urban places, as there are many family stressors, such as mental health problems, alcohol dependency, and a history of family violence. However, those rural families who have been reported to Child Protective Services are more likely than those reported in urban areas to experience high family stress ${ }^{1}$ and financial difficulties. ${ }^{2}$

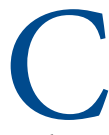
hild maltreatment is a pervasive problem in the United States. In 2007, officials investigated approximately 1.9 million reports of alleged child maltreatment. ${ }^{3}$ Child maltreatment generally refers to an act or failure to act by a parent, caregiver, or other person that involves physical or emotional harm, neglect, sexual abuse, and exploitation or imminent harm to a child. ${ }^{4}$ Encouragingly, from 1990 to 2007, the number of substantiated cases of child sexual abuse and physical abuse declined by 52 percent. The number of child neglect cases, however, declined by only 6 percent. ${ }^{5}$

Most studies have found about equal rates of child maltreatment in rural and urban America. ${ }^{6}$ Our own analyses show that child maltreatment in rural families tends to mirror that in urban families. (We use the term rural to refer to all locations outside metropolitan areas. This includes both places adjacent and not adjacent to metropolitan places. Urban refers to metropolitan places.) The types of abuse are similar, as are many family stressors, such as mental health problems, alcohol dependency, and a history of family violence. However, rural families that have been reported to Child Protective Services (CPS) are more likely than those in urban areas to be experiencing high family stress and financial difficulties.

\section{Distribution of Child Maltreat- ment in Rural and Urban Areas}

Child neglect, or the failure by the caregiver to provide needed age-appropriate care, ${ }^{7}$ is the most common type of reported child maltreatment in rural America (see Table 1). Approximately one-half of reports are for neglect. In contrast, a little more than one-fourth of the reports are for physical abuse. Over a quarter of the children are reported for more than one type of child maltreatment no matter where they live. Experiencing multiple forms of maltreatment has more pronounced negative effects on children than experiencing a single type of abuse. ${ }^{8}$

Table 1: Prevalence and cases of Child abuse reported to Child Protective Services in rural AND URBAN AMERICA BY MOST SERIOUS ABUSE TYPE

$\underline{\text { Percent of cases }}$ Rural Urban

Most severe abuse

\begin{tabular}{|lrr|}
\hline Physical abuse & 28.23 & 26.97 \\
\hline Sexual abuse & 13.90 & 10.46 \\
\hline Neglect & 46.26 & 46.52 \\
\hline Other abuse type $^{1}$ & 11.61 & 16.05 \\
\hline Experienced multiple abuse types & 25.64 & 29.53 \\
\hline Sample size & 910 & 4138 \\
\hline
\end{tabular}

${ }^{1}$ Includes emotional, abandonment, moral/legal maltreatment, educational maltreatment, exploitation, and other 
Both the distribution of child maltreatment and the profile of families reported to CPS are remarkably similar in rural and metropolitan America, excepting some striking differences. First, given the larger populations, there are far more cases reported in urban than rural America (our data include 4,138 cases in metropolitan places and 910 cases in rural places). Rural children who are reported for abuse or neglect are more likely to grow up in single-parent homes (39 percent versus 31 percent), and urban children are more often living in unsafe neighborhoods. ${ }^{9}$ The distribution of race/ethnicity also varies by place. Most rural children reported to CPS are white (nearly 80 percent), whereas metropolitan children are more diverse (41 percent white, 31 percent black, 21 percent Hispanic, and 7 percent other). There are no significant gender or poverty differences among those reported in both areas. Poverty is particularly prevalent in reports of maltreatment. Nearly 40 percent of children in both urban and rural areas who are reported to CPS live in poverty.

\section{Similarities in Risk Factors for Child Maltreatment}

Figure 1 reveals remarkable similarities by locale in the risk factors associated with reports to CPS:

- About one-half of the families had a prior report to CPS

- Nearly one-half of the caregivers have mental health impairments

- Most caregivers (more than 60 percent) report low social support

FIGURE 1: RISK FACTORS IN THE HOMES OF CHILDREN reported to Child Protective Services with SIMILARITIES BY PLACE

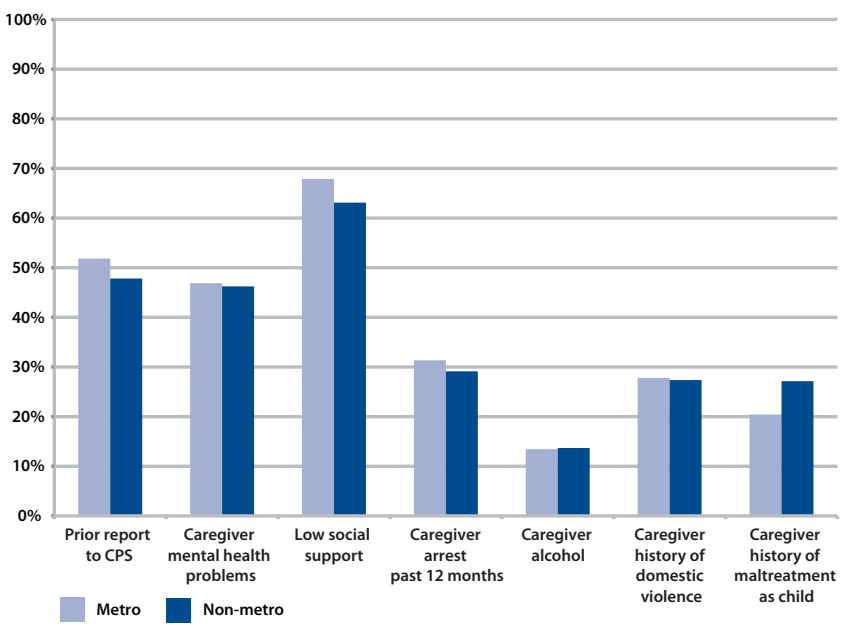

- Nearly one-third of caregivers were arrested during the past year

- More than one in ten caregivers have problems with alcohol

- One in five caregivers has a history of domestic violence

- More than one in five caregivers were themselves maltreated as children

The high prevalence of prior reports to CPS suggests we could do more to help families avoid future problems. In addition, caregiver difficulties suggest that parenting supports and interventions may be an important step in preventing child maltreatment.

FIgURE 2: RISK FACTORS IN THE HOMES OF CHILDREN reported to Child Protective Services With DIFFERENCES BY PLACE

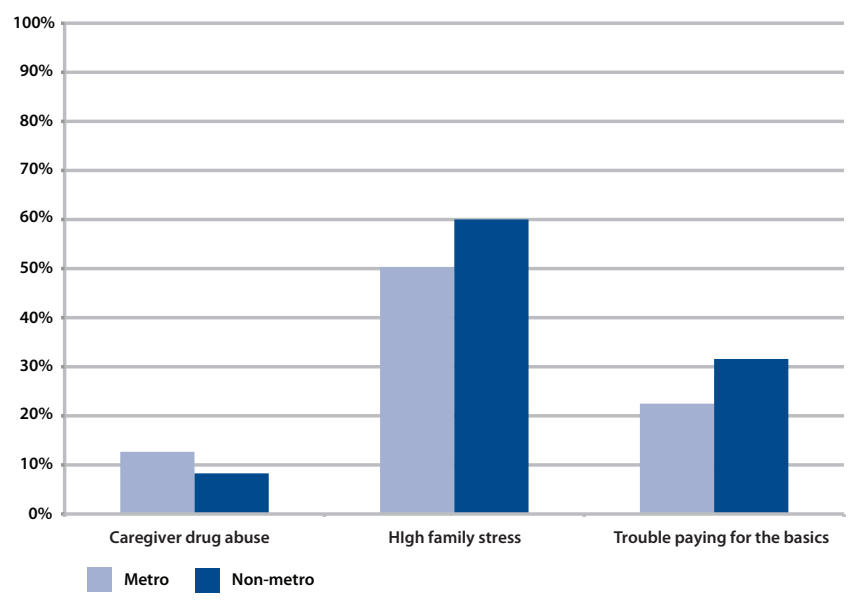

\section{Differences in Risk Factors by Locale}

Despite the similarities between rural and urban America, we also find some important statistically significant differences $(\mathrm{p}<0.05)$, as shown in Figure 2.

- More than 60 percent of caregivers in rural America with a report of child maltreatment experience high family stress compared with 50 percent in urban areas

- Nearly one in three rural families reported to CPS have trouble meeting basic financial needs compared with just over one in five urban families reported to CPS

- Drug use is less common in the homes of rural children reported to CPS (8 percent versus 13 percent) 


\section{Chronic Stressors in}

\section{Rural Families}

It appears that rural families face chronic stressors and may have been struggling for a long time. Child maltreatment is only one of the problems they confront and perhaps one of the consequences of those problems. For rural families, isolation and lack of adequate services to help cope may present formidable obstacles to healthy family life.

The risk factors for child maltreatment highlight the importance of intervention and prevention programs. If interventions were designed to identify and assist struggling families sooner, we would likely see rates of child abuse decline. Because of the many similarities in risk factors between families in urban and rural areas, universal prevention programs that offer parents a wide range of assistance tailored to their needs would be beneficial. These services include social support, mental health services, and general parenting help. This analysis suggests that families reported to CPS are dealing with multiple stressors in their lives, regardless of where they live. It would therefore be beneficial if prevention services, such as home visitation programs, were more accessible to all families.

\section{Data}

The data from this project come from the National Survey of Child and Adolescent Well-Being (NSCAW), a nationally representative sample of children who had a maltreatment report that resulted in a child welfare investigation. Baseline investigations were conducted between October 1999 and December 2000 for 5,501 children aged 0 to 16 years. NSCAW used a stratified two-stage cluster sampling strategy that included ninety-two child protection agencies in thirty-six states. The data include cases that were both unfounded and substantiated at baseline. Additional information on the NSCAW study design and sampling procedure has been previously published. ${ }^{10}$ Face-to-face interviews were conducted with children, current caregivers, caseworkers, and teachers at baseline (about four months following completion of the index investigation). We used county-level USDA classification categories to determine metropolitan status. Codes one to three are considered metropolitan, or urban; codes four to eight are considered nonmetropolitan, or rural. ${ }^{11}$ For confidentiality reasons, respondents in the most rural places (USDA continuum code nine) were not included in the NSCAW sampling frame. Thus, our rural sample is not representative of those in the most remote places. Because there are no national guidelines for substantiating cases of child abuse and jurisdictions have their own criteria, this analysis included all cases reported to CPS, regardless of whether cases were substantiated by the caseworker.
Statistics were computed using survey weights to produce national estimates.

\section{ENDNOTES}

1. Caseworkers answered the following question: "At the time of the investigation, was there high stress on the family? This may have resulted from things like unemployment, drug use, poverty, or neighbor violence? Yes or no." When caseworkers responded affirmatively, families are coded as having high stress.

2. Caseworkers answered the following question: "At the time of the investigation, did the family have trouble paying for basic necessities such as food, shelter, clothing, electricity, or heat? Yes or no." When caseworkers responded affirmatively, families are coded as having financial difficulty.

3. U.S. Department of Health and Human Services, Administration on Children, Youth, and Families, "Child Maltreatment 2007” (Washington, DC: U.S. Government Printing Office, 2009).

\section{Ibid.}

5. Lisa Jones and David Finkelhor, "Updated Trends in Child Maltreatment, 2007” (Durham, NH: Crimes Against Children Research Center, 2009).

6. See, for example, Joseph C. Cappelleri, John Eckenrode, and Jane L. Powers, “The Epidemiology of Child-Abuse: Findings from the Second National Incidence and Prevalence Study of Child Abuse and Neglect," American Journal of Public Health 83 (1993):1622-1624; Howard Dubowitz et al., "Type and Timing of Mothers' Victimization: Effects on Mothers and Children," Pediatrics 107(4) (2009): 728-735; JoAnn Ray and Susan Murty, "Rural Child Sexual Abuse Prevention and Treatment," Human Services in the Rural Environment 13 (1990): 24-29.

7. U.S. Department of Health and Human Services, Administration on Children, Youth and Families. "Child Maltreatment 2007” (Washington, DC: U.S. Government Printing Office, 2009).

8. C. Arata et al., "Single Versus Multi-Type Maltreatment: An Examination of the Long-Term Effects of Child Abuse," Journal of Aggression, Maltreatment and Trauma 11, No. 4 (2005): 29-51; T. Stevens et al., "Variables Differentiating Singly and Multiply Victimized Youth: Results from the National Survey of Adolescents and Implications for Secondary Prevention," Child Maltreatment 10, No. 3 (2005): 211-223.

9. To determine neighborhood safety, caregivers completed nine questions from the Abridged Community Environment Scale.

10. NSCAW Research Group, "Methodological Lessons from the National Survey of Child and Adolescent Well-Being: The First Three Years of the USA's First National Probability Study of Children and Families Investigated for Abuse and Neglect," Children and Youth Services Review 24 (2002): 513-541. 
11. Measuring Rurality: Rural-Urban Continuum Codes is available at http://www.ers.usda.gov/briefing/rurality/ ruralurbcon/.

\section{ACKNOWLEDGMENTS}

We are grateful for assistance in preparing this brief from Kristi Gozjolko, a graduate student working at the Carsey Institute, and for feedback from Mil Duncan, Curt Grimm, and Terri Rippett at the Carsey Institute; David Finkelhor, professor of sociology and director of the Center for Research on Crimes Against Children at the University of New Hampshire; Elliot Smith, associate director of the National Data Archive on Child Abuse and Neglect at Cornell University; and Barbara Ray at Hired Pen for editorial assistance.

\section{ABOUT THE AUTHORS}

Beth Mattingly is director of research on vulnerable families at the Carsey Institute and research assistant professor of sociology at the University of New Hampshire. Her research addresses the consequences of family violence; the intersections of gender, work and family; and family wellbeing (beth.mattingly@unh.edu).

Wendy A. Walsh is a research assistant professor of sociology at the Crimes against Children Research Center at the University of New Hampshire. Her research examines how communities prevent and respond to child abuse and evaluates the criminal justice response to child abuse (wendy. walsh@unh.edu).
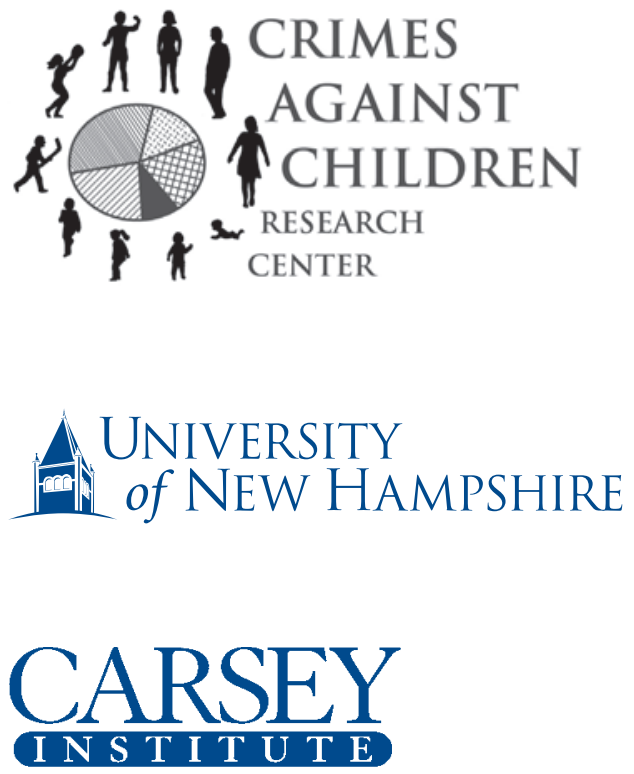

Building knowledge for families and communities

The Carsey Institute conducts policy research on vulnerable children, youth, and families and on sustainable community development. We give policy makers and practitioners timely, independent resources to effect change in their communities.

This work was supported by the Annie E. Casey Foundation's initiative to strengthen rural families, the W. K. Kellogg Foundation, and an anonymous donor.

Huddleston Hall

73 Main Street

Durham, NH 03824

(603) $862-2821$

www.carseyinstitute.unh.edu 